\title{
Bioactivity and Extraction Method with Ultrasonication of Nelumbo nucifera Linn. Anti Aging Drinks
}

\section{Buavaroon Srichaikul*}

\section{Buavaroon Srichaikul*}

Faculty of Public Health, Mahasarakham University, Mahasarakham 44150, THAILAND.

\section{Correspondence}

\section{Buavaroon Srichaikul}

Faculty of Public Health, Mahasarakham University, Mahasarakham 44150,

THAILAND.

E-mail: buacanada@gmail.com

History

- Submission Date: 03-05-2020;

- Review completed: 28-06-2020;

- Accepted Date: 01-07-2020.

DOI : 10.5530/pj.2020.12.155

Article Available online

http://www.phcogj.com/v12/i5

\section{Copyright}

(C) 2020 Phcogj.Com. This is an openaccess article distributed under the terms of the Creative Commons Attribution 4.0 International license.

\begin{abstract}
Introduction: Nelumbo nucifera Linn. Flowers health drinks currently are one of the popular demand globally in Thailand and all over the world. There are plenty of substandard or over claimed of antioxidant content labeled at health drink bottles. The consumers do not obtain enough health benefits anti-oxidant contents which are destroyed by heat during their production process. Methods: This study aimed to evaluate the optimization of extraction including water, $40 \%$ and $50 \%$ ethyl alcohol using maceration and ultra-sonication method to obtain the highest antioxidant activity compared with DPPH, FRAP and ABTS methods were investigated including total phenolic and flavonoid contents by HPLC in different period of time. The analysis of acute toxicity in white wistar rats by oral administrating of Nelumbo nucifera Linn. flowers extract was testing for after $24 \mathrm{~h}$ and $14 \mathrm{~d}$. Results: It was found that Nelumbo nucifera Linn. flower extract drink consisted of high contents of gallic acid, catechin and rutin by HPLC method. Nelumbo nucifera Linn flowers Highest Total Phenolic compound in Nelumbo nucifera Linn. flower extracts with sonicating with $50 \%$ ethanol was $0.954639 \pm$ 0.109672 . Highest Total flavonoids in Nelumbo nucifera Linn. flower extracts macerating in $50 \%$ ethanol at day 5 th was $1.100275 \pm 0.777271$.and the sonication with $40 \%$ ethanol was $0.394283+/-0.51175$. Conclusions: The result of acute toxicity analysis showed no toxicity. Nelumbo nucifera Linn. flower extract drinks which are safe as a health drink for consumers. The further market analysis with sensory test should be essential for further research.

Key words: Nelumbo nucifera Linn., Flower extract drink, Ultra sonication Extraction, Phenolic content, Flavonoids, Acute Toxicity, HPLC.
\end{abstract}

\section{INTRODUCTION}

Nelumbo nucifera Linn. Usually grows in Thailand which commonly was named as "Dok Bua". It is classified in Nelumbonaceae Family. Nelumbo nucifera, also known as Indian lotus, sacred lotus, bean of India aquatic plant. Under favorable circumstances its seeds may remain viable for many years. $^{1-6}$ The oldest recorded lotus germination being from that of seeds 1,300 years old recovered from a dry lakebeds in northeastern China which were prepared anti-aging drink consisted of 1-3 $\mathrm{kg}$ with 1.5 liter of water and lliter of Nelumbo nucifera Linn. Flower extract extracted from 100300 gram of Nelumbo nucifera Linn. Flower which could yield 0.4 liter of flower extrac. ${ }^{7}$ Found that Nelumbo nucifera Linn. can inhibit information of lipid peroxide and protein in oxidation and aldose reductase which can inhibit severity of diabetic disease from the active ingredient extracted 6"Alpinia officinarum. ${ }^{8}{ }^{8}$ It also was found that antioxidant activity of Nelumbo nucifera Linn. can decrease the stress oxidation from free radical scavenging enzymes and lipid per oxidation by inducing lead acetate in rat. M.M. Jeevanee et al. found that methanol, acetone, $(50 \%, 90 \%$ and $100 \%)$ can be used for the extraction of phenolic volatile oils including anti-oxidant such as flavonoid, anthocyanin from Nelumbo nucifera Linn. Flowers'. The analysis of highest total phenolic extraction was at the amount of $1431 \mathrm{mg} / \mathrm{QE} 100 \mathrm{gm}$. using
$50 \%$ acetone as extraction solvent. This study was aimed at analyzing the active ingredients of Nelumbo nucifera Linn. flower extracts using HPLC such as antioxidant and total phenolic compound, flavonoid ,and also investigated the comparison of anti-oxidant activities by DPPH, FRAP and ABTS method using different kinds of extraction solvents such as water $50 \%$ ethanol and with ultra-sonication method. ${ }^{2}$ The study also investigated the analysis of acute toxicity of Nelumbo nucifera Linn. Flower extract in white vista rats as experimental group and control group.

\section{MATERIALS AND METHODS}

\section{Sample selection}

The complete and healthy petal shape of Nelumbo nucifera Linn were selected as a samples from Nelumbo nucifera Linn. farm in Samut Songkram province, Central of Thailand during October, 2015.The samples were dried in air at normal room temperature and also dried in hot air oven at $50 \mathrm{C}$ until completely dried. The dried sample of Nelumbo nucifera Linn. flowers were kept in closed container at room temperature for preparing in next step of extractions. ${ }^{2,3}$

\section{Extraction of Samples}

Extraction by Ultra sonication Method with $40 \%$ ethanol, $50 \%$ ethanol. Ultra sonication Method is the method for extraction using high frequency ultrasonic sound for extraction purpose using small

Cite this article: Srichaikul B. Bioactivity and Extraction Method with Ultrasonication of Nelumbo nucifera Linn. Anti-Aging Drinks. Pharmacogn J. 2020;12(5):1097-103. 
amounts of time without using high temperature .The sample was extracted with ultra-sonication extraction for 30 minutes. Solvents used were $40 \%$ ethanol, $50 \%$ ethanol. The proportion of samples extraction solvent was 1: $50 \mathrm{w} / \mathrm{v}$. Then the solution was filtered using filter paper no.0. The filtered solution was then evaporated using evaporator at $50 \mathrm{C}$ and was transferred to be proceeded in Freeze Dried equipment for drying. The data of fresh and dried weight of yields were recorded before and after freeze dried method. The freeze dried coarse samples were kept in closed container and was waiting for further analyzing steps.

Extraction with water by Ultra sonication Method. The sample was extracted with ultra-sonication extraction for 30 minutes Solvents used were purified water. The proportion of samples extraction: solvent was 1: $50 \mathrm{w} / \mathrm{v}$. Then the solution was filtered using filter paper no.0. The data of fresh and dried weight of yields were recorded before and after maceration with water then samples were kept in a closed container and was waiting for further analyzing steps. ${ }^{2}$

Extraction with ethanol maceration for 7 days the samples of Nelumbo nucifera Linn flower was macerated with $50 \%$ ethanol and $40 \%$ ethanol for 7 days. The coarse extracted powder was collected daily for 7 days and the proportion of samples extraction: solvent was 1: $50 \mathrm{w} / \mathrm{v}$. Then the solution was filtered using filter paper no.0. The data of fresh and dried weight of yields were recorded before and after maceration with water then samples were kept in a closed container and was waiting for further analyzing steps.

\section{Bioactivity analysis}

\section{Total phenolic content analysis}

The standardized gallic acid at concentration of 12.5- 1,000 micro gram $/ \mathrm{ml}$ in $80 \%$ ethanol and also the sample of Nelumbo nucifera Linn. flower extract at concentration of $1 \mathrm{mg} / \mathrm{ml}$ in $80 \%$ ethanol were prepared on 3 replications the analysis was carried in 96-well microtiterplate added with $25 \mathrm{ml}$ of samples and standardized solution. 125 microgram /liter of Follin Ciocalteu reagent was added and rested for 5 minutes at room temperature then added $75 \mathrm{~g} / \mathrm{l} \mathrm{Na} 2 \mathrm{Co} 3$ for 100 microgram and distilled water qs. To 300 microgram and the solution was rested at room temperature for 2 hours until completing the reaction. The final solution was brought to be measured the concentration and the absorbance with spectrometer (micro plate) at 760 nanometer wavelength. Graph were plotted between the relationship of concentration of samples and the absorbance of light in order to calculate the result of total phenolic content related to gallic acid equivalent (microgram gallic acid /mg extract).

\section{Flavonoid content analysis}

Standardized Quercetin at conc. of 12.5 -1000 microgram / $\mathrm{ml}$ in $80 \%$ ethanol was prepared. Samples of Nelumbo nucifera Linn. Flower extract were prepared at concentration of $1 \mathrm{mg} / \mathrm{ml}$ in $80 \%$ ethanol in 3 replications. All were tested in 96 well plates by adding 25 micro liter of ample and $75 \mathrm{micro}$ liter of $95 \%$ ethanol. Then 5 micro liters of $10 \%$ $\mathrm{AlCl} 3,5$ micro liter of $1 \mathrm{~mol} \mathrm{K3COOH}$ were added to the solution and qs. Added to 140 micro liters with distilled water. The solution was rested at room temperature for 30 minutes until completing the reaction. The final solution was brought to be measured the concentration and the absorbance with spectrometer (micro plate) at 415 nanometer wavelength. Graph was plotted and interpreted in linear equation to identify the relationship between standardized quercetin concentration and the concentration of sample related to the absorbance light. The absorbance value from given sample was interpreted and changed to standard graph of flavonoid content which was equivalent to quercetin (microgram quercetin /mg extract). ${ }^{5,6}$

\section{Analysis of anti-oxidant activity by DPPH method}

Nelumbo nucifera Linn. Flower Extract were prepared in 5 concentrations (15-500 microgram $/ \mathrm{ml}$ ) of ethanol in test tube. DPPH was prepared in 60 microgram /liter of ethanol. The 750 micro liter of flower extract was prepared in 750 micro liter of DPPH and were kept at room temperature for complete reaction for 20 minutes. Then the solution was brought to be measured with Spectrometer using UV light at $517 \mathrm{~nm}$ wavelength. The $\%$ radical scavenging was calculated with the formula below:

$\%$ radical scavenging $=($ A control $-\mathrm{A}$ sample $) \times 100($ A control $)$

A control is absorbance value of UV light of control

A sample is absorbance value of UV light of sample

The graph was plotted between concentrations of Nelumbo nucifera Linn. flower extract and \% radical scavenging in order to calculate EC 50 value. All data were collected and recorded in order to calculate \% of antioxidant and standard deviation of percent of radical scavenging. ${ }^{?}$

\section{Analysis of antioxidant activity by FRAP assay method}

Nelumbo nucifera Linn. flower extract was prepared at concentration of $1 \mathrm{mg} / \mathrm{ml}$. The FRAP reagent was also prepared which consisted of acetate buffer: TPTZ (2, 4, 6 -tripyridyl -striazine) and ferric chloride. The proportion of the 3 reagents was 30:1:1. Then 100 micro liter of Nelumbo nucifera Linn. flower extract was mixed with 3,000 micro liter of FRAP reagent in the test tube in order to complete reaction. The mixture was brought to measure the absorbance at $593 \mathrm{~nm}$. Wavelength in 10 minutes with spectrometer and compared the standard curve of the graph of Feso4 in order to evaluate the Fe2 (Fe equivalent) for 6 replications. Feso4 solutions were prepared at 0.1, 0.25, 0.5, 1.0, 2.5 and 5.0 millimol. Each test tube contained 100 micro liters reacted with 3,000 micro liters FRAP reagent. The solution was brought to measure the absorbance value at $593 \mathrm{~nm}$ wavelength of UV light in order to build the standard graph and showed the relationship with concentration of Feso4. Data collection was recorded and calculated the comparison of $\mathrm{Fe} 2$ equivalent of samples and antioxidant activity reagent (ascorbic acid).

\section{Analysis of antioxidant activity by ABTS assay method}

The standard Trelox solution was prepared at concentration of 12.5 $-1000 \mathrm{microgram} / \mathrm{ml}$ in $80 \%$ ethanol and samples of Nelumbo nucifera Linn. flower extract was also prepared at concentration of $1 \mathrm{mg} / \mathrm{ml}$ in $80 \%$ ethanol with 3 replication. The ABTS solution was prepared by mixing $7 \mathrm{mM}$ ABTS with 2.45 milli mol potassium per sulfate of the same ratio in the distilled water and the solution was kept in dark at room temperature for 6 hours and was dissolved with $\mathrm{CH} 3 \mathrm{OH}$ until obtaining the absorbance at 1.00 with $734 \mathrm{~nm}$. Of UV wavelength. The test was carried in the 96 well plate with standard sample at 150 micro liter. 150 micro liter of ABTS solution was added and kept in room temperature for 6 minutes for completion of reaction. The solution was brought to measure the concentration of Nelumbo nucifera Linn. flower extract sample against the absorbance with Spectrometer (micro plate reader) at $734 \mathrm{~nm}$. Wavelength. The absorbance relating to Nelumbo nucifera Linn. flower extract and standard graph to convert and to calculate equivalent value to Trolox solution. (Trolox equivalent) or (microgram Trolox /mg extract)

\section{Statistical analysis}

Descriptive statistic used were mean, standard error of means (SEM) the standard error of the mean (SEM) measures how far the sample mean of the data is likely to be from the true population mean. The SEM is always smaller than the SD. standard errors are often used in clinical experimental studies. ${ }^{4}$ 


\section{Standard error of the mean}

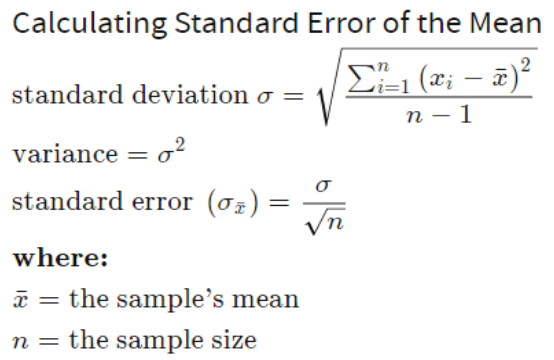

SEM is calculated by taking the standard deviation and dividing it by the square root of the sample size.

The formula for the SD requires a few steps:

First, take the square of the difference between each data point and the sample mean, finding the sum of those values. Then, divide that sum by the sample size minus one, which is the variance. And finally, take the square root of the variance to get the SD. ${ }^{4}$

Inferential statistic used were one-way analysis of variance, ANOVA and testing the homogeneity of variance using 1 -sample K-S and testing of normal distribution using RUN -test.We found that the result of population and sample were normal distribution therefore the sample was capable to further test for hypothesis evaluation. The statistic of testing the hypothesis of antioxidant activity between standard solution and sample solutions extracted from different kind of solvent solutions was one- way ANOVA. The result was found that there was statistical significant different at p-value 0.05 . Therefore, we have used SPSS version 15 to evaluate the average mean scores in each pair of sample solutions test using Scheffe "s test.

\section{Acute toxicity analysis of Nelumbo nucifera Linn. flower extract}

Preparation of raw material of Nelumbo nucifera Linn. Flowers Samples of Nelumbo nucifera Linn. flower extract flowers were collected from Aumphawa farm, Samutsongkram, Thailand. We selected the healthy petals for running the experiment. The Nelumbo nucifera Linn. flower samples were cleaned with purified water and dried in hot air oven at 50 C. Dried flowers were blended to powder form.

The powder of dried Nelumbo nucifera Linn. flowers were macerated in $50 \%$ ethanol using the proportion of 1:50. They were extracted by ultrasonication method for 30 minutes and were filtered with thin white cloth and filtered second time with filtered paper.

The filtered portion was brought to be evaporated using rotary evaporator for drying the filtered portion free from ethanol solvent and was brought to precede freeze drying process.

The freeze dried powder was given to white vista rat orally (by mixing with $0.5 \%$ tween $80 \%$ solvent) in order to test acute toxicity further.

Preparation of experimental white vista rats Female and male albino vista rats were used in acute toxicity analysis of Nelumbo nucifera Linn. flower extracts with 200-250 gm. Weight. Before the experiment, we have to control room temperature for keeping and feeding the experimental rats at 25 and $-2 \mathrm{C}$, relative humidity at $40-60 \%$, exposing them with the light 12 hours daily and feeding them with food and water through the experiment ${ }^{11}$.

\section{Experimental analysis in acute toxicity}

We used randomized control trial in this study with Fixed Effect model using 2 factors which were normal control albino vista rats with $0.5 \%$ Tween 80 as a control group and in $2000 \mathrm{mg}$ of orally induced
Nelumbo nucifera Linn. flower extracts per $1 \mathrm{~kg}$ of albino vista rats using orogastric tube through their mouths as an experimental group. All rats' had 200-250 gm. weight. The volume used was $1 \mathrm{ml}$ of Nelumbo nucifera Linn. flower extracts to each experimental rat groups and $1 \mathrm{ml}$ of $0.5 \%$ Tween 80 to each control rat groups.

Data observation symptoms of rats for acute toxicity analysis We observed and recorded abnormality symptoms of experimental rats after 24 hours and after 14 days , 2 times daily observations continuously such as breathing, ingestion, excretion, defecation, motility, suture, disorientation, anorexia, vomiting ,the changes in weight including the records the numbers of mortality rats . At the end of experiment, we had preceded the cervical dislocation of all rats and used their blood samples from cardiac ejections and brought them for hematological analysis. The statistical used were mean, percentage, standard deviation, standard error mean using SPSS.

\section{Total Phenolic contents of Nelumbo nucifera Linn. Flower extract analysis}

We followed the highest antioxidant analysis which composed the compounds of Acetonitrite (A), $0.01 \%$ trifluoroacetic acid (B), the flow rate analysis at $1.0 \mathrm{ml} / \mathrm{min}$ under specific gradients as shown in table 1 .

We have injected the samples of Nelumbo nucifera Linn. flower extracts into 10 micro liter and compared with the standard substance of $(1=$ gallic acid, $2=$ catechin, $3=$ chlorogenic acid, $4=$ rutin, $5=$ ferulic acid $6=$ quercetin) at concentration of $50-500 \mathrm{microgram} / \mathrm{ml}$, at 280 $\mathrm{nm}$, wavelength of UV light and calculated Total Phenolic contents in Nelumbo nucifera Linn. flower extracts. ${ }^{9}$

\section{RESULTS}

Fresh weight / Dried weight of Nelumbo nucifera Linn. flowers

The data was collected after hot air processing method. The table 2 showed \% yield of fresh weight and dried weight of Nelumbo nucifera Linn. flowers.

\section{Comparative of Bioactivity analysis results of Nelumbo nucifera Linn. flower extracts}

The result of DPPH, ABTS FRAP) antioxidant activity analysis and the content of active ingredients for Total Phenolic content, Total Flavonoid content (Table 3 ) by 6 extractions, macerations with different concentration of solvents against time and ultrasonication process. All results have been illustrated in this study (Table 3).

\section{Table 1: Time and Ratio of solvents.}

\begin{tabular}{cc}
\hline Time (minutes) & Ratio of solvents (A \%) \\
\hline $0-5$ & $20-25$ \\
$5-10$ & 25 \\
$10-12$ & $25-30$ \\
$12-15$ & $30-40$ \\
$15-22$ & $40-30$ \\
$22-27$ & $30-20$ \\
\hline
\end{tabular}

Table 2: Fresh weight and dried weight of Nelumbo nucifera Linn flowers.

\begin{tabular}{cccc}
\hline Plant & $\begin{array}{c}\text { Fresh weight } \\
\text { (gm.) }\end{array}$ & Dry weight (gm.) & \% Yield \\
\hline $\begin{array}{c}\text { Nelumbo nucifera } \\
\text { Linn }\end{array}$ & 20.0243 & 1.8927 & 9.4520158 \\
\hline
\end{tabular}

The result of \% fresh weight / dried weight of Nelumbo nucifera Linn. flowers was 9.45 . 
The antioxidant activity analysis by DPPH method was found that the sonication with $40 \%$ ethanol gave the highest antioxidant activity and also maceration with water which were $0084374+/-0.009675$ and $0.119194+/-0.003876$.

The antioxidant activity analysis by ABTS method was found that the sonication with water and maceration with $40 \%$ ethanol at day 6 th gave the highest antioxidant activity which were $0.352254+/-0.034724$ and $0.323169+/-0.002147$ respectively.

The antioxidant activity analysis by FRAP method was found the highest antioxidant activity using macerated $50 \%$ ethanol at day 7 th and showed the result was $4.346863+/-0.525966$.

Highest Total Phenolic compound in Nelumbo nucifera Linn. flower extracts with sonicating with $50 \%$ ethanol was $0.954639 \pm 0.109672$.

Highest Total flavonoids in Nelumbo nucifera Linn. flower extracts macerating in $50 \%$ ethanol at day 5 th was $1.100275 \pm 0.777271$.and the sonication with $40 \% \mathrm{EtOH}$ was $0.394283 \pm 0.511175$.

\section{Result in Acute toxicity analysis of Nelumbo nucifera Linn. flower extract}

We have observed and recorded result in Acute toxicity analysis of Nelumbo nucifera Linn. (Figures 1 and 2) flower extract which showed no abnormality symptoms in experimental rats after 24 hours and after
14 days with 2 times daily observations continuously such as breathing, ingestion, excretion, defecation, motility, suture, disorientation, anorexia, vomiting, the changes in weight including the records the numbers of mortality rats. At the end of experiment we had proceeded the cervical dislocation of all rats and used their blood samples from cardiac ejections and brought them for hematological analysis such as Blood Glucose, BUN, Creatinine, Uric acid, Cholesterol, Triglyceride, LDL, HDL, total protein, albumin, globulin, total bilirubin, AST, ALT including the comparison of internal organ weights of control and experimental group of albino vista rats such as liver, kidney, heart and lung (as shown in tables 4-6.The statistical used were mean, percentage, standard deviation, standard error mean using SPSS.The result of acute toxicity analysis of Nelumbo nucifera Linn. flower extracts in albino vista rats showed no sign of death or abnormality in abino vista rats with no toxicity.

\section{The results of active ingredients from HPLC analysis}

The active ingredients were investigated such as Gallic acid, Catechin, Ferulic acid and Rutin (table 7). The analysis of Total Phenolic contents were selected from highest oxidant activity from the extraction in order to analyze the compositions using residues of apples from the manufacturer which composed of Acetonitrile (A) and $0.01 \%$ trifluoroacetic acid (B), rate of flow was calculated at $1.0 \mathrm{ml} / \mathrm{min}$ under gradient conditions as follows:

Table 3: Shown the optimization of antioxidant activity of Nelumbo nucifera Linn flower extracts and the content of active ingredients for Total Phenolic content, Total Flavonoid content (shown in table 3) by 6 extractions with different time, maceration solvents and ultrasonication process.

\begin{tabular}{|c|c|c|c|c|c|}
\hline Extraction Method & DPPH & $\begin{array}{c}\text { ABTS } \\
\text { (MEAN +/- S.D.) }\end{array}$ & FRAP & $\begin{array}{c}\text { Total Phenolic MEAN } \\
\text { +/- S.D. }\end{array}$ & $\begin{array}{l}\text { Total Flavonoid } \\
\text { MEAN +/- S.D }\end{array}$ \\
\hline $\begin{array}{l}\text { 1.Sonication with } 50 \% \text {. } \\
\text { EtOH }\end{array}$ & & & & $\begin{array}{c}0.954639+/- \\
0.109672\end{array}$ & \\
\hline \multicolumn{6}{|l|}{ 2.Sonicate $40 \% \mathrm{EtOH}$} \\
\hline 3.Maceration with water & $\begin{array}{l}0084374+/-0.009675 \\
0.119194+/-0.003876\end{array}$ & $\begin{array}{c}0.352254+/- \\
0.034724\end{array}$ & & & \\
\hline $\begin{array}{l}\text { 4.Maceration with } 50 \% \\
\text { EtOH Day } 5\end{array}$ & & & & & $1.100275+/-0.777271$ \\
\hline $\begin{array}{l}\text { 5.Maceration with } 40 \% \\
\text { EtOH Day } 6\end{array}$ & & $\begin{array}{l}0.323169+/- \\
0.002147\end{array}$ & & & \\
\hline $\begin{array}{l}\text { 6..Maceration with } 50 \% \\
\text { EtOH Day7 }\end{array}$ & & & $4.346863+/-0.525966$ & & \\
\hline
\end{tabular}

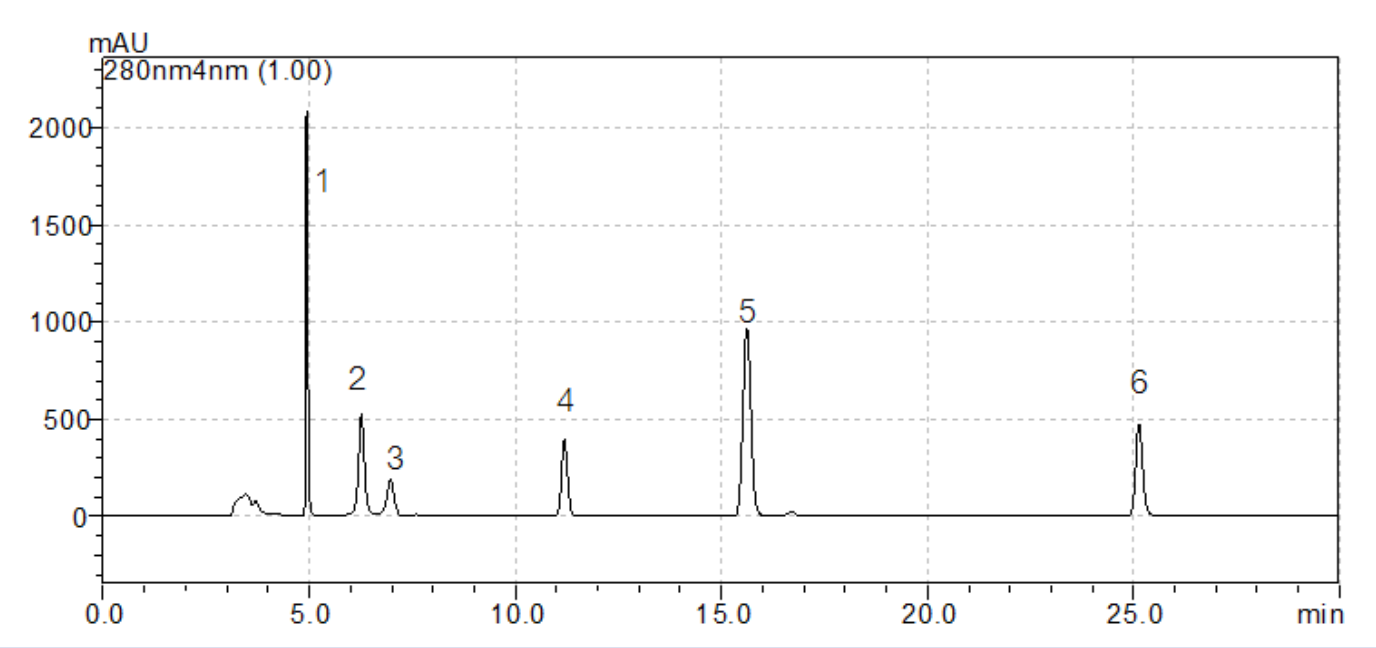

Figure 1: Showed chromatogram of standardized compounds (standard no.1= gallic acid, $2=$ catechin, $3=$ chlorogenic acid, $4=$ rutin, 5 = ferulic acid, $6=$ quercetin). ${ }^{2}$ 


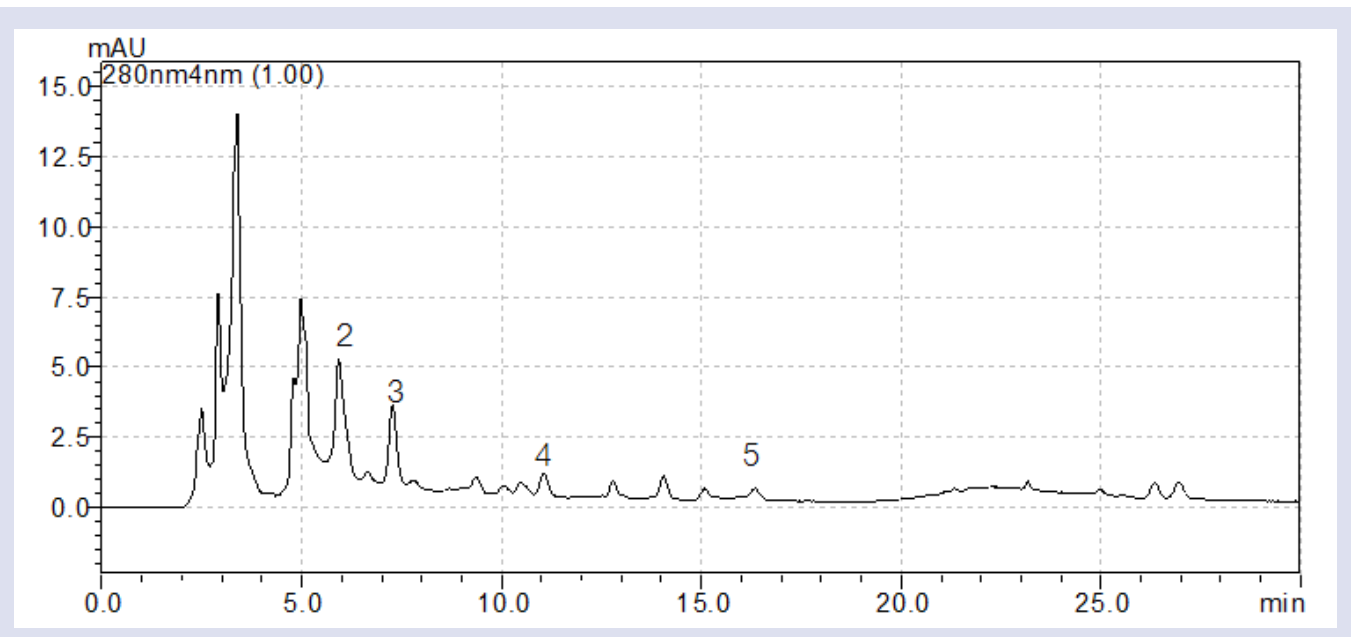

Figure 2: Showed chromatogram of Nelumbo nucifera Linn. flower extract ( $1=$ gallic acid, $2=$ catechin, $3=$ chlorogenic acid, $4=$ rutin, 5 = ferulic acid, $6=$ quercetin $).^{2}$

Table 4: Showed the result of hematological values in wistar rats by Nelumbo nucifera Linn. flower extract $(2,000 \mathrm{mg} / \mathrm{kg}$ body weight).

\begin{tabular}{ccc}
\hline Parameters & Control group & Nelumbo nucifera Linn. \\
\hline Glucose $(\mathrm{mg} / \mathrm{dl})$ & $146.60 \pm 8.15^{\mathrm{a}}$ & $149.37 \pm 12.83^{\mathrm{a}}$ \\
BUN(mg/dl) & $26.48 \pm 1.58^{\mathrm{a}}$ & $27.24 \pm 1.28^{\mathrm{a}}$ \\
Creatinine $(\mathrm{mg} / \mathrm{dl})$ & $0.84 \pm 0.02^{\mathrm{a}}$ & $0.88 \pm 0.03^{\mathrm{a}}$ \\
Uric(mg/dl) & $3.72 \pm 0.28^{\mathrm{a}}$ & $3.76 \pm 0.34^{\mathrm{a}}$ \\
Cholesterol $(\mathrm{mg} / \mathrm{dl})$ & $78.00 \pm 5.95^{\mathrm{a}}$ & $74.13 \pm 5.74^{\mathrm{a}}$ \\
TG $(\mathrm{mg} / \mathrm{dl})$ & $123.60 \pm 13.41^{\mathrm{a}}$ & $120.26 \pm 9.16^{\mathrm{a}}$ \\
HDL $(\mathrm{mg} / \mathrm{dl})$ & $16.60 \pm 1.12^{\mathrm{a}}$ & $15.61 \pm 0.72^{\mathrm{a}}$ \\
\hline
\end{tabular}

${ }^{a}$ statistical significant difference at $\mathrm{p}$ value $\geq 0.05$ compared with control group.

Table 5: Showed the result of hematological values in wistar rats by Nelumbo nucifera Linn. flower extract $(2,000 \mathrm{mg} / \mathrm{kg}$ body weight) continued.

\begin{tabular}{ccc}
\hline parameters & Control group & Nelumbo nucifera Linn. flower extract \\
\hline LDL(mg/dl) & $38.00 \pm 5.31^{\mathrm{a}}$ & $37.83 \pm 3.54^{\mathrm{a}}$ \\
Total protein(mg/dl) & $6.06 \pm 0.12^{\mathrm{a}}$ & $6.08 \pm 0.10^{\mathrm{a}}$ \\
Albumin(g/dl) & $3.86 \pm 0.06^{\mathrm{a}}$ & $3.78 \pm 0.06^{\mathrm{a}}$ \\
Globulin(g/dl) & $2.20 \pm 0.07^{\mathrm{a}}$ & $2.17 \pm 0.10^{\mathrm{a}}$ \\
Total bilirubin (mg/dl) & $0.30 \pm 0.03^{\mathrm{a}}$ & $0.36 \pm 0.07^{\mathrm{a}}$ \\
$\mathrm{AST}(\mathrm{U} / \mathrm{L})$ & $78.60 \pm 2.60^{\mathrm{a}}$ & $81.32 \pm 7.25^{\mathrm{a}}$ \\
$\mathrm{ALT}(\mathrm{U} / \mathrm{L})$ & $29.20 \pm 0.96^{\mathrm{a}}$ & $33.97 \pm 3.18^{\mathrm{a}}$ \\
\hline
\end{tabular}

astatistical significant difference at $\mathrm{p}$ value $\geq 0.05$ compared with control group.

Table 6: Showed the result of internal organ weight (gm.) of wistar rats by Nelumbo nucifera Linn. flower extract $(2,000 \mathrm{mg} / \mathrm{kg}$ body weight).

\begin{tabular}{ccc}
\hline Organ & Control group & Nelumbo nucifera Linn. flower extract \\
\hline Liver & $4.84 \pm 0.31^{\mathrm{a}}$ & $4.93 \pm 0.52^{\mathrm{a}}$ \\
Kidneys & $0.76 \pm 0.04^{\mathrm{a}}$ & $0.80 \pm 0.05^{\mathrm{a}}$ \\
Heart & $0.44 \pm 0.02^{\mathrm{a}}$ & $0.42 \pm 0.03^{\mathrm{a}}$ \\
Lungs & $0.58 \pm 0.04^{\mathrm{a}}$ & $0.56 \pm 0.03^{\mathrm{a}}$ \\
\hline
\end{tabular}

${ }^{a}$ statistical significant difference at $p$ value $\geq 0.05$ compared with control group. 
Table 7: Injected Nelumbo nucifer Linn. flower extract 10 microliter to the system and compared with the standardized compound of $1=$ gallic acid, 2= catechin, 3= chlorogenic acid, 4= rutin, $5=$ ferulic acid, $6=$ quercetin at concentrations of $50-500$ microgram $/ \mathrm{ml}$ using 280 nanometer wavelength for analysis of active ingredient compounds of total phenolic compounds in Nelumbo nucifera Linn. flower extract as showed in Table 12 the analysis of active compounds by HPLC method.

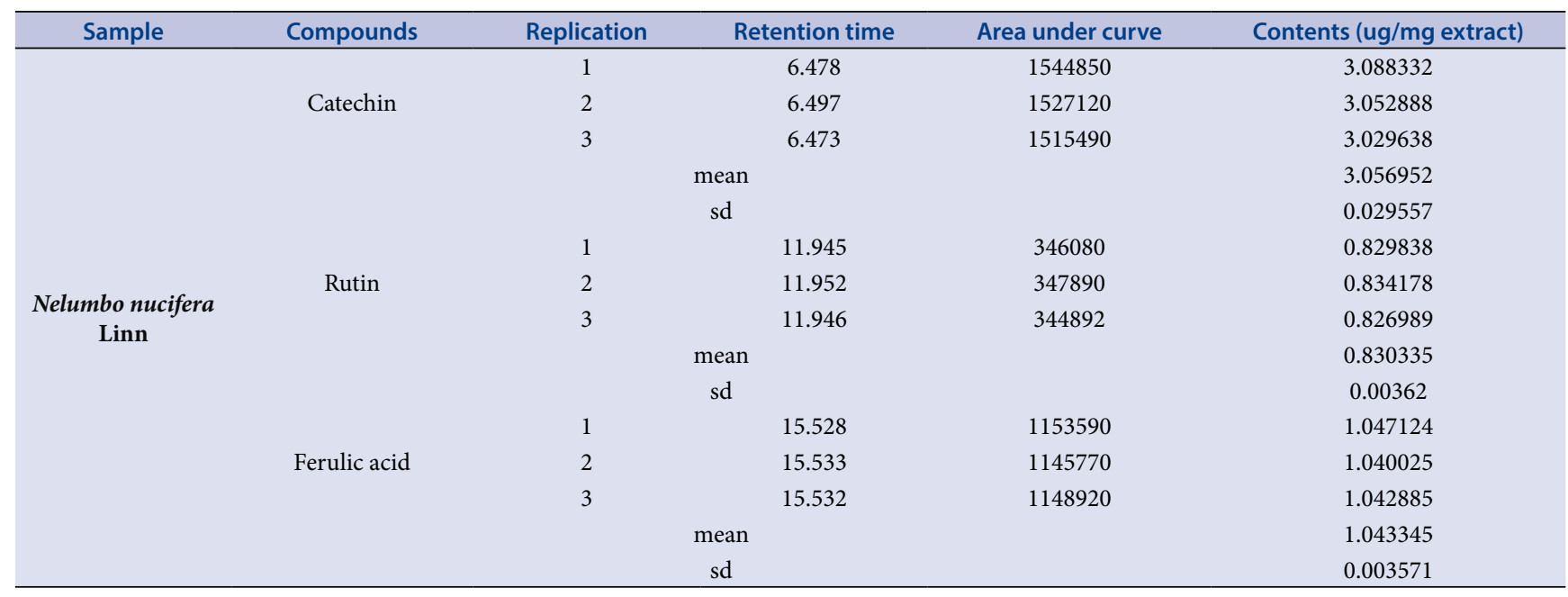

\begin{tabular}{cc}
\hline Time (minutes) & Ratio of solvent A (\%) \\
\hline $0-5$ & $20-25$ \\
$5-10$ & 25 \\
$10-12$ & $25-30$ \\
$12-15$ & $30-40$ \\
$15-22$ & $40-30$ \\
$22-27$ & $30-20$ \\
\hline
\end{tabular}

\section{CONCLUSIONS}

The antioxidant activity analysis by DPPH method was found that the ultrasonication with $40 \%$ ethanol gave the highest antioxidant activity by maceration with water which were $0084374+/-0.009675$ and $0.119194+/-0.003876$. The antioxidant activity analysis by ABTS method was found that the sonication with water and maceration with $40 \%$ ethanol at day 6 th gave the highest antioxidant activity which were $0.352254+/-0.034724$ and $0.323169+/-0.002147$ respectively. Thee antioxidant activity analysis by FRAP method was found the highest antioxidant activity using macerated $50 \%$ ethanol at day 7 th and showed the result was $4.346863+/-0.525966$. Highest Total Phenolic compound in Nelumbo nucifera Linn. flower extracts with sonicating with $50 \%$ ethanol was $0.954639 \pm 0.109672$. Highest Total flavonoids in Nelumbo nucifera Linn. flower extracts macerating in $50 \%$ ethanol at day 5 th was $0.100275 \pm 0.777271$.and the sonication with $40 \% \mathrm{EtOH}$ was $0.394283 \pm 0.511175$. The HPLC results from Nelumbo nucifera Linn. Flower extracts showed that mean of Catechin, Rutin and Ferulic acid contents (microgram/mg extract) were 3.056952+/- 0.029557 (Mean +/ - SD.) and 0.830335+/- 0.00362 (Mean +/- SD.) and 1.043345 $+/-0.003571$ respectively. We have observed and recorded result in acute toxicity analysis of Nelumbo nucifera Linn. flower extract which showed no abnormality smptoms in experimental wistar rats after 24 hours and after 14 days with 2 times daily observations continuously. The statistical used were mean, percentage, standard deviation, standard error mean using SPSS. We suggest that the samples of antiaging Nelumbo nucifera Linn. flower extract drinks are safe and can be developed as a health drink in the market. The further market analysis with sensory test should be essential for developing the quality relating to the customer needs in the further research

\section{ABBREVIATIONS}

$\mathrm{d}=$ day; sd. = standard deviation; HPLC = High Performance liquid chromatography; EtoH $=$ Ethanol; FRAP method $=$ Ferric Reducing anti poxidant power; ABTS method $=2,2$-azino-bis (3-ethylbenzthiazoline-6-sulphonic acid; DPPH method $=2$,2'-azinobis (3-ethylbenzthiazoline-6- sulphonic acid); nanometer $=\mathrm{nm}$; AST $=$ aspartate amino transferase; ALT $=$ alanine transaminase; $\mathrm{LDL}=$ low density lipoprotein; $\mathrm{HDL}=$ high density lipoprotein; $\mathrm{TG}=$ Triglecerride; $\mathrm{BUN}=$ blood urea protein; $\mathrm{ml}=$ millilitre.

\section{DECLARATION}

1.The ethical committee had approved the project and waived since the experiment concerned the proceed and methodology not involving human so no formal ethic approval.

2. Consent for publication Not applicable.

3. Data availability are available from corresponding author with permission to public.

\section{Competing interests}

The author that they have no Competing interests in this section.

\section{Funding}

This research was supported by Thailand Research Fund 2017.

\section{Authors contributions}

\section{ACKNOWLEDGEMENTS}

The authors acknowledge Central laboratory of Mahasarakham University, Mahasarakham Flower Plantation Agriculturists, Mahasarakham province, Thailand. Also, the research team would like to thank TRF (Thailand Research Fund) for supporting his research project.

\section{REFERENCES}

1. Abdelwahab SI. Chemical composition, antioxidant and antibacterial properties of the essential oils of Nelumbo nucifera Linn Kochummen. J Sci Food Agric. 2010;90(15):2682-8.

2. Bunleu Sung thong, Chirapha Butiman, Kusuma Jitsaeng. Optimizied Ultrasonication -Asissted Extraction of, Antioxidant from Mulberry (Morus Alba L.) Leaves using Multiple Linear Regression Analysis. International Journal of Pharmacy and Pharmaceutical Sciences. 2014;6(2):914-7.

3. Sungthong B, Srichaikul B. Antioxidant Activities, Acute Toxicity and Chemical Profiling of Torch Ginger (Etlingera elatior Jack.) Inflorescent Extract. Pharmacog J. 2018;10(5):979-82.

4. Caleb Silver, Standard Error of the Mean vs. Standard Deviation: The Difference.2019 may 7: Retrieved from URL https://www.investopedia.com/ ask/answers/042415/what-difference-between-standard-error-means-andstandard-deviation.asp 
5. Faridahanim Mohd Jaafar. Analysis of Essential oil of Leaves, Stems, Flowers and Rhizomes of Etlingera Elatior (JACK) R. M. Smith. The Malaysian Journal of Analytical Sciences. 2007;11(1):269-73.

6. LU Luan-mei, LIN Jin-shui, XIE Zhi-ming. Effects of Different Preservative Solution on Cut Flowers of, Acta Horticulturae Sinica. 2010;(8):1351-6.

7. Pawinee Deetae, Sittiwat Lertsiri. Antioxidant and anti-glycation properties of Thai herbal teas in comparison with conventional teas. Food Chemistry. 2012;133(3):953-9
8. Soon Sung Lim, Hye-Sook Kim, and Dong-Ung Lee Bull. Korean Chem Soc. 2007;28(12):2495-7.

9. Lim TK. Flowers, Edible Medicinal and Non-Medicinal Plants: 8:1-71.

10. Jackie T, Haleagrahara N, Chakravarth S. BMC Research Notes. 2011.

11. Kunanusorn $P$, Panthong $A$, Pittayanurak P. Acute and subchronic oral toxicity studies of Nelumbo nucifera stamens extract in rats. J Ethnopharmacol. 2011;134(3):789-95.

\section{ABOUT AUTHOR}

\section{Buavaroon Srichaikul}

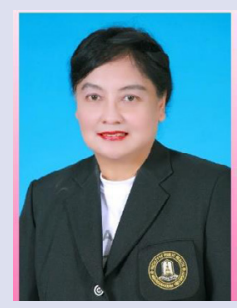

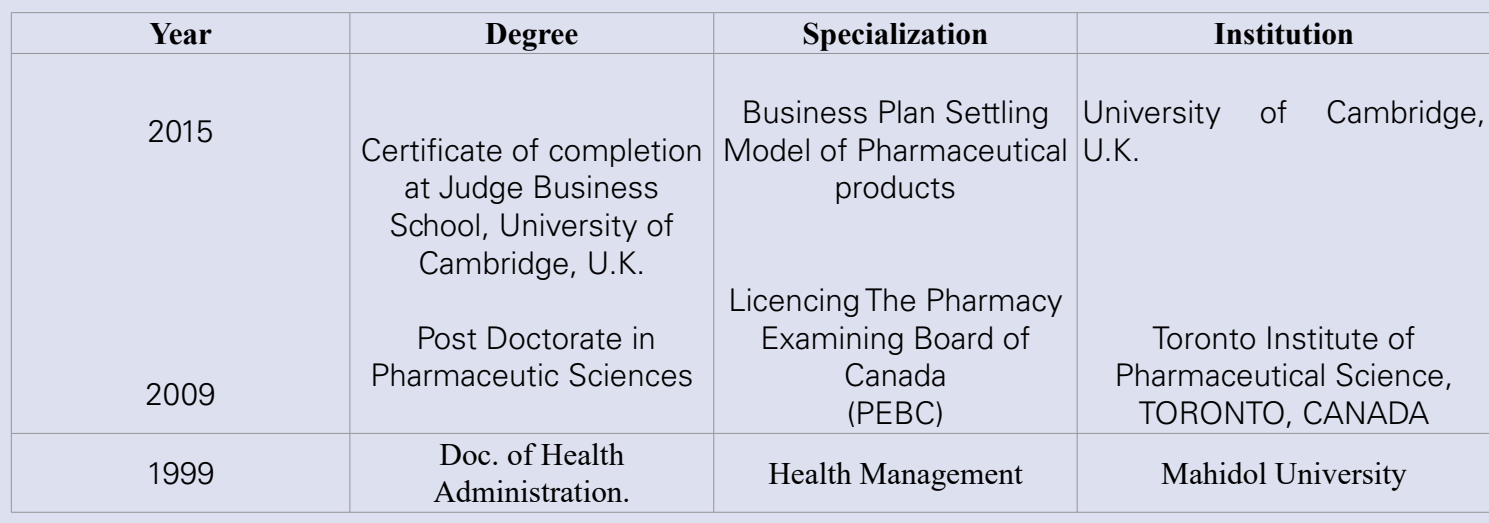

\section{Working Experience}

2018

Assoc.Prof. Dr. at Faculty of Public Health.

Mahasarakham University, Thailand.

2003-2009

Lecturer at Toronto Institution of Pharmaceutical

Science, Toronto, Canada.

Science, Toronto, Canada.

I have 24 manuscripts published internationally.

Cite this article: Srichaikul B. Bioactivity and Extraction Method with Ultrasonication of Nelumbo nucifera Linn. Anti-Aging Drinks Pharmacogn J. 2020;12(5):1097-103. 